\title{
PREVALENCE OF STREPTOCOCCAL PHARYNGITIS AMONG SCHOOL CHILDREN OF POKHARA VALLEY, NEPAL
}

\author{
Shrestha $\mathrm{L}^{1}$, Khattri J B K $\mathrm{K}^{1}$, Brahmadathan K N ${ }^{1}$, Nagra J S
}

\section{ABSTRACT}

Group A Beta Haemolytic Streptococcal (GABHS) infections and their sequelae Rheumatic fever (RF) and Glomerulonephritis (GN) have a world wide distribution and pose an important health problem. Present study intended to find out the prevalence ofGABHS pharyngitis among school children in the Pokhara Valley, Nepal. It was a cross sectional, observational study. During 7 months period total 750 children were examined from six government primary schools. $25.3 \%$ were found to have symptoms of clinical pharyngitis and the prevalence of GABHS pharyngitis was $7.2 \%$ among these school children. GABHS pharyngitis found more among male and in the age group of 3-10 years. This study was undertaken to highlight the problems of GABHS throat infections in Nepalese school children and also to stress on the urgent need for control programme for streptococcal disease complex.

\section{Key Words: Prevalence, Streptococcal pharyngitis, School children.}

\section{INTRODUCTION}

Group A beta-hemolytic streptococci (GABHS ) are the usual cause of acute streptococcal throat infection, either pharyngitis or tonsillitis, in children between 5-15 years. Such infections can lead to the late or non-suppurative sequelae, namely, rheumatic fever (RF) leading to RHD and acute post-streptococcal glomeronephritis (AGN ). ${ }^{1}$ $\mathrm{RF}$ and $\mathrm{AGN}$ are major health problems in the developing world. The incidence ofRF declined in industrialized countries, since the 1950's and now has an annual prevalence of 0.5 cases per 1,00,000 children. In developing countries it remains an endemic disease with annual incidence ranging from 100 to 200 per $1,00,000$ school children and is a major cause of cardio-vascular mortality. ${ }^{2} \mathrm{RF}$ is reported to occur in 1-3 percent of streptococcal throat infections of children living in underprivileged conditions. ${ }^{3}$

1. Manipal College of Medical Sciences, Pokhara, Nepal.

Address for correspondence : Dr. Lochana Shrestha, Dept. of Community Medicine

Manipal College of Medical Sciences, P.O. Bo: 155, Pokhara, Nepal.

Tel: 977-61-26416-20, Ext. 182, Email: sulav@mail.com.np 
GABHS are normal inhabitants of the oropharynx and skin. Colonization of the throat with GABHS may occur in $10 \%-20 \%$ of normal school aged children. These children are carriers and do not get actively infected nor are at risk of developing RF. ${ }^{4}$ However, throat culture is the most useful laboratory aid in the microbiological diagnosis of acute tonsillitis or pharyngitis especially when blood collection for antibody studies become problematic. Thus in the presence of clinical symptoms of pharyngitis, throat culture becomes mandatory for instituting primary penicillin prophylaxis.

In Nepal, there is no school survey program for the control of RF now, nor there is such a program, being planned for the future either. To initiate a control programme, data on the prevalence and incidence of GABHS pharyngitis are required. However only scant information is available in Nepal regarding the magnitude of this problem. Therefore, a study was carried out to determine the prevalence of GABHS pharyngitis among school children in the Pokhara Valley.

\section{MATERIALS AND METHODS}

A cross-sectional study was conducted from JanJuly2001 in six government primary schools in the northern part of Pokhara valley, Nepal. All children were examined for signs of tonsillitis and pharyngitis. Those with positive signs of pharyngitis and/or tonsillitis, history of sore throat and not receiving any antibiotics in the preceding two weeks, were selected for taking throat swabs. The tonsillar and pharyngeal mucosa were rubbed vigorously with sterile cotton swab applicator avoiding the surrounding tissues. The throat swabs were inoculated onto sheep blood agar in the Microbiology Laboratory at the Manipal Teaching Hospital (MTH) and incubated for 24 hours. Beta hemolytic colonies were identified as streptococci by Gram stain and confirmed as GABHS by bacitracin sensitivity. All children were also examined for other infections, and demographic/ anthropometric data were collected. Penicillin prophylaxis was given for those children who were found to be positive for GABHS. After 3 weeks they were followed up in their houses, to detect any sign of rheumatic fever and rheumatic heart disease.

\section{RESULTS}

A total of 750 children from six primary schools were examined (Table I). These primary schools covered Kindergarten to 5th standard. Two schools namely, Gyan Bhumi Primary School and Bal Jyoti School accounted for 309 of the 750 children. Girls ( $n=383$ ) outnumbered the boys $(n=367)$ in four of the six schools.

Table I: Age and sex distribution of students in 6 different schools. $(n=750)$

JNMA, January - March, 2002, 41 
Of the 750 children, $190(25.3 \%)$ were found to have symptoms of tonsillopharyngitis (Clinical pharyngitis) (Table II). It varied from $16.8 \%$ (School 6) to $36 \%$ (School 3). The overall prevalence of GABHS pharyngitis among these children was $7.2 \%$ while it varied from $2.5 \%$
(School 6) to $13 \%$ (School 2). Fifty-four (28.4\%) of the 190 cases of tonsillitopharyngitis seen were due to GABHS.

Clinical pharyngitis cases were found to be more among girls $(26.1 \%)$ than boys $(24.5 \%)$ whereas

Table III: Sex distribution of clinical and GABHS Pharyngtis in 6 schools.

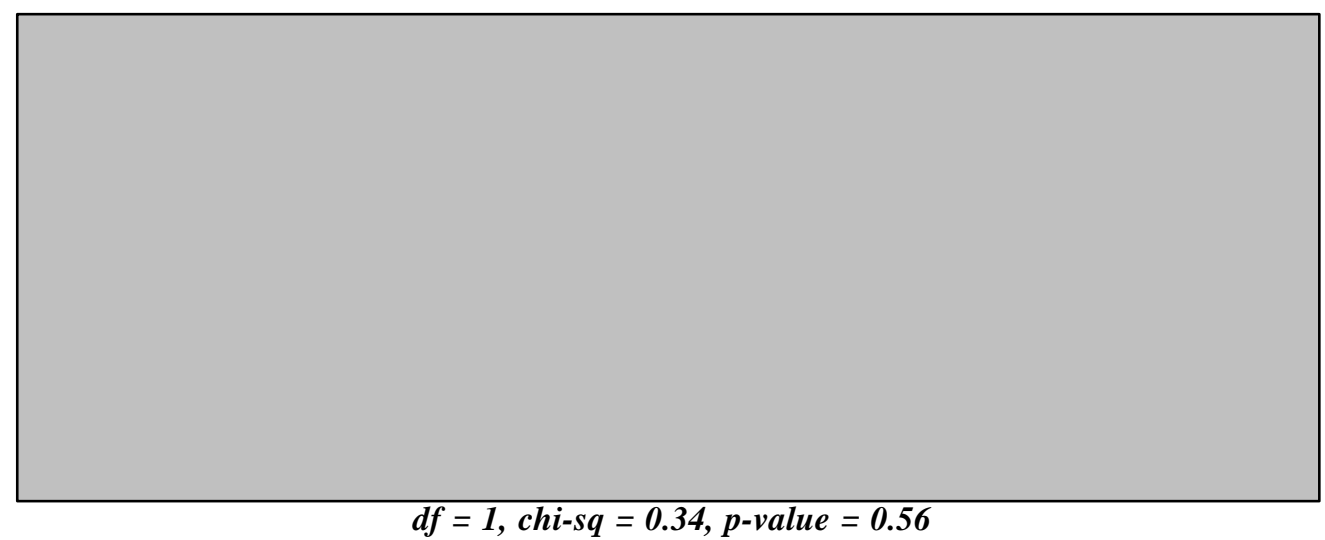

GABHS pharyngitis were found to be more in boys (7.6\%) than in girls (6.7\%) (Table III). However in Gyan Bhumi Primary School with a this difference was not statistically significant. $(\mathrm{p}=0.56)$. Regarding age distribution, corresponding higher prevalence of GABHS pharyngitis also in this age group. A similar, but not statistically significant, difference was found both clinical pharyngitis and GABHS pharyngitis were found to be more among the 3-10 year age group. Interestingly, a higher prevalence of clinical in Dibya Jyoti School as well. In the follow-up study, no RF/AGN cases were seen among children who had GABHS pharyngitis. 
Table IV: Age distribution of pharyngotonsillitis and GABHS cases in 6 different schools.

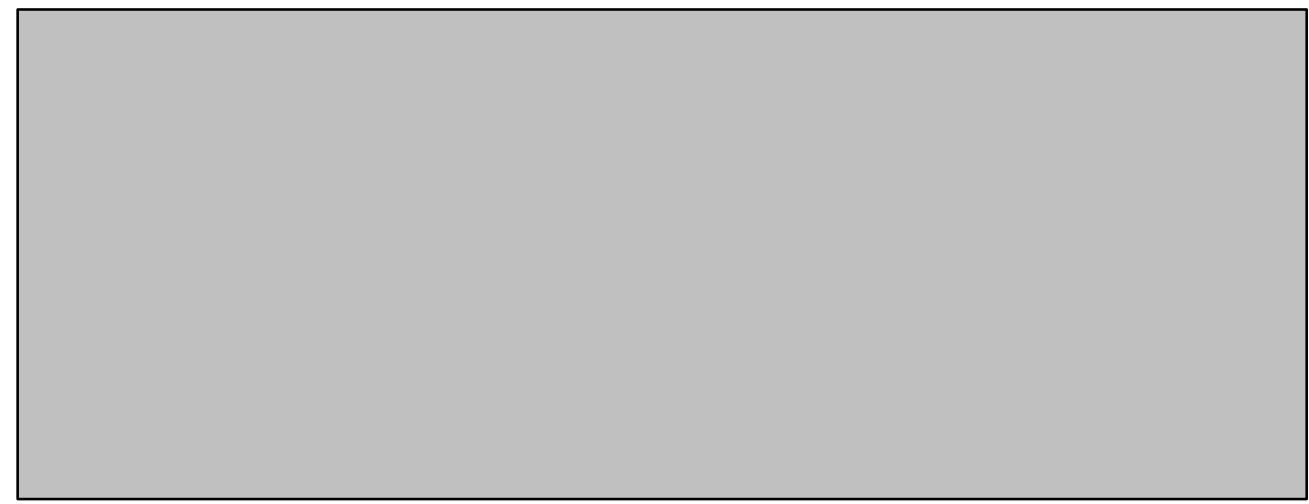

$d f=1$, chi-sq $=0.01, p-$ value $=0.92$

\section{DISCUSSSION}

GABHS throat infection is the most important causes of RF and RHD. Prevalence rate of RF and RHD in communities of developing countries is still very high. Prevalence rate in Nepal is not known. Various hospital statistics show that RHD is the commonest heart disease in Nepal. This study shows that the prevalence of GABHS among school going children is $7.2 \%$. Whereas in studies conducted in Dhaka, ${ }^{5}$ Thailand $^{6}$ shows the prevalence of GABHS, $22 \%$ and $18 \%$ respectively among school children. $25.3 \%$ of pharyngotonsillitis cases seen in present study, which is very similar to studies conducted in various countries like United States ${ }^{7} 30 \%$, Osaka $20.6 \%$, England $^{2} 20 \%$ and Iran $^{9} 30 \%$.

Antibody studies are microbiologically important, both for documentation of GABHS pharyngitis as well as a clinical diagnosis of RF/RHD. We were unable to perform antibody studies on children with GABHS pharyngitis for fear of compliance. This is one of the first few school-survey studies carried out in this region and therefore, we wanted to develop a good rapport with the children before we could do intensive studies among them. The present study shows a high prevalence rate of
GABHS pharyngitis among school children. Many studies have shown a high carrier rate among school children residing in communities' endemic for GABHS infections. Since our primary objective was only to determine the prevalence of GABHS pharyngitis among these children, we did not do carrier state studies among them.

This study presents high prevalence of GABHS positive cases among male and in the age group of 3-10 years, which is comparable to the findings of similar studies conducted in different parts of world. In this study, RF cases were not detected during follow-up; this might be either due to implementation of penicillin prophylaxis for GABHS positive cases or might be due to the inadequate sample size studied. It is a wellrecognized fact that occurrence ofRF is only to the extent of $1-3 \%$ of streptococcal infection.

Our study shows that the prevalence of GABHS pharyngitis in developed countries does not differ from other developing countries. RF and RHD have declined significantly in North America and Western Europe. ${ }^{10}$ This decline can be attributed to improved socio-economic status, adequate penicillin prophylaxis, development of physical barriers to the spread of streptococci, and less 
overcrowding. ${ }^{11}$ In India, a streptococcal reference system has already been established and primary prevention method for RF and RHD, namely control of streptococcal infections, is also going on. ${ }^{11}$ Similar control programs should be actively employed to prevent the high prevalence of GABHS pharyngitis and their sequelae.

\section{CONCLUSION}

Prevalence of Group A beta hemolytic streptococcal from the throat of symptomatic Nepalese schoolchildren has been reported for the first time. Further epidemiological studies on streptococcal disease complex are needed to substantiate the findings of the study. As methods for streptococcal control progamme have now become cost effective, such programme should be incorporated into any prevention methods for control of RF and RHD, and children below 11 years may require a special attention regarding prevention of streptococcal infection.

\section{ACKNOWLEDGEMENT}

Authors are grateful to the members of Department of Community Medicine and medical students of seventh semester, Manipal Teaching Hospital, for their kind co-operative help in collection of data.

\section{REFERENCES}

1. KaplanEL, Krugman S. Streptococcal infections. Group A. In: Krugmem S, K-atz SL, Gershon AA. Infections disease of children. Mosby-Yearbook, Inc. company, 1992: 474.

2. Oliver-C. Rheumatic fever- Is it still a problem?. J Anti microb chemother. 2000; 45 suppi
3. ParkK. Rheumatic Heart disease. In: Textbook of preventive and Social Medicine.Sixteen edition. M/ s Banarsidas Bhanot, 1167, premnagar, Jabalpur (India). 1997 : 279

4. James K. todd. Group A streptococcus . In : Behrman RE, kliegman RM, J enson HB. Nelson Text book of Pediatrics, 16th edition. W.B. Saunders Company .2000; 802

5. Likitnukuls S, Prappal N, Tatiyakavee k et al. Risk factors of Streptococcal colonization in school age children. Southeast Asian J trop Med Public health. 1994; 25 (4):664-71

6. Faroq QO, Rashid AK, Ahmed J et al. Prevalence of Streptococcal sore throat in the school childrens ofDhaka. Bangladesh Med Res Coum Bull. 1995 ; 21 (3): 87-97.

7. Woods WA, Carter CT, Scholager TA. Detection of Group A Streptococcal in children under 3 years of age with pharyngitis. Pediatr emerg care 1999; 15 (5): 338-40.

8. Okuyuma M, Sagayama $Y$, Nakajima K. An epidemiological study of group A, B, C and G hemolytic Streptococcal isolated fromelementary school in the recent 12 years. KansenshogakuZasshi. 1994; 68 (5): 656-64.

9. Jasir A, Noorani A, Mirsalehian A, Schalen C. I solation rates of streptococcus pyogenes in patients with acute pharyngotonsillitis and among healthy school children in I ran. Epidemiol Infect. 2000; 124(1): 47-51.

10. Lundin SR, Amett J T, Dowler G G, Brentlinger D C. Streptococcal phryngitis in college health population. J Am Coll Health 1984; 32: 227-230.

11. Community control of rheumatic heart disease in developing countries: @strategies for prevention and control. WHO Chron 1980; 34: 389-395.

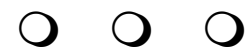

